\title{
A five-year retrospective study of maternal mortality in a tertiary referral centre
}

\author{
Meenal S. Sarmalkar, Arun H. Nayak*, Shameel Faisal, Abhakumari
}

\begin{abstract}
Department of Obstetrics and Gynecology, Lokmanya Tilak Municipal Medical College and General Hospital, Sion, Mumbai, Maharashtra, India
\end{abstract}

Received: 21 February 2021

Revised: 04 April 2021

Accepted: 05 April 2021

\section{*Correspondence:}

Dr. Arun H. Nayak,

E-mail: drarunhnayak@hotmail.com

Copyright: $@$ ( the author(s), publisher and licensee Medip Academy. This is an open-access article distributed under the terms of the Creative Commons Attribution Non-Commercial License, which permits unrestricted non-commercial use, distribution, and reproduction in any medium, provided the original work is properly cited.

\section{ABSTRACT}

Background: The objectives of this study were to calculate the maternal mortality ratio (MMR) and the causes of maternal deaths in an urban tertiary care institution.

Methods: A retrospective study of 305 maternal deaths over the period from January 2014 to December 2018 was carried out. Data was analysed using frequency and percentage with the help of Microsoft Excel 2019.

Results: The MMR during the study period was 666.75 per 100,000 live births. Majority of maternal deaths (130, $42.62 \%)$ occurred in age group 21-25 years. Maximum number of women $(288,94.1 \%)$ came from urban area. Majority of maternal deaths occurred in referred cases $(238,78.03 \%)$ to our institution. Majority were registered cases $(235,77.0 \%)$. Maximum women $(201,62 \%)$ died in the postnatal period. Majority of maternal deaths $(222,72.79 \%)$ occurred within 7 days of admission. Direct and indirect causes contributed to $40 \%$ and $59.67 \%$ of maternal deaths. Among the direct causes of maternal deaths, haemorrhage $(45,14.75 \%)$ ) was the leading causes for death followed by hypertensive disorders $(42,13.77 \%)$ and sepsis $(11,9.02 \%)$. Tuberculosis $(34,18.68 \%)$ was the most common indirect cause of maternal mortality in our study followed by hepatitis $(30,16.48 \%)$ and respiratory conditions $(25$, $9.02 \%)$.

Conclusions: Adequate surveillance of tuberculosis in the antenatal period, health education of pregnant women, proper antenatal, intranatal and emergency obstetric care in the first referral unit with proper blood banking facilities and timely referral to the tertiary care institute will help to lower the high death rate.

Keywords: MMR, Obstetric haemorrhage, Preeclampsia, Tuberculosis

\section{INTRODUCTION}

Maternal death is the leading cause of death for women in reproductive age group. The index of the quality of health care delivery system of a country as a whole or in part is reflected by its maternal mortality ratio (MMR). The global MMR has declined from 342 in 2000 to 211 in 2017 , representing a $38 \%$ reduction since $2000 .{ }^{1}$ Maternal Mortality Ratio of India has declined from 254 in 20042006 to 130 in 2014-2016, 122 in 2015-2017 and 113 in 2016-2018. ${ }^{2,3}$ There is a great difference in MMR within the country states and districts depending upon the socioeconomic factors and educational status. This study was conducted to determine the maternal mortality ratio and to study the leading causes of maternal deaths at an urban tertiary care institute.

\section{METHODS}

A retrospective observational study of all maternal deaths was conducted in the department of Obstetrics and Gynaecology of Lokmanya Tilak Municipal Medical College and General Hospital, Sion, Mumbai during the period from January 2014 to December 2018. Antenatal papers, Indoor records and death summaries of all maternal deaths occurring in this period were reviewed. 


\section{Inclusion criteria}

All antepartum, intrapartum and postpartum deaths within 42 days of delivery admitted at tertiary care hospital.

\section{Exclusion criteria}

Postpartum deaths occurring 42 days after termination of pregnancy, maternal deaths due to burns, accidents, suicide and poisoning.

Parameters like age, parity, residence, educational status, occupation, general condition on admission, vital parameters, antenatal care, gestational age, delivery details, complications, interventions, blood and blood products transfusion details, admission to death interval, causes of death and level of delay were studied. The neonatal outcome in terms of live births and stillbirths was also studied. Ethics approval was taken prior to conduct of study.

\section{Statistical analysis}

Data are presented as frequency and percentage with the help of Microsoft Excel 2019.

Maternal mortality ratio for the study period was calculated by using the formula-

$$
\text { MMR }=\frac{\text { Total no. of maternal deaths }}{\text { Total no. of live births }} \times 100000
$$

\section{RESULTS}

During the study period there were 45,744 live births and 305 maternal deaths giving a cumulative maternal mortality ratio of 666.75 per 1,00,000 live births.

Table 1: Year wise maternal mortality ratios.

\begin{tabular}{|llll|}
\hline Year & $\begin{array}{l}\text { Total deaths } \\
\text { per year }\end{array}$ & $\begin{array}{l}\text { No. of live } \\
\text { births }\end{array}$ & MMR \\
\hline $\mathbf{2 0 1 4}$ & 83 & 10332 & 803.33 \\
\hline $\mathbf{2 0 1 5}$ & 63 & 10014 & 629.12 \\
\hline $\mathbf{2 0 1 6}$ & 59 & 10057 & 586.66 \\
\hline $\mathbf{2 0 1 7}$ & 59 & 8168 & 722.33 \\
\hline $\mathbf{2 0 1 8}$ & 41 & 7173 & 571.59 \\
\hline Total (2014-18) & 305 & 45,744 & 666.75 \\
\hline
\end{tabular}

Table 1 shows the year wise distribution of live births, maternal deaths and yearly MMR. The maternal mortality ratio ranged from $629.12 / 1,00,000$ to $803.33 / 1,00,000$ with an average of $666.75 / 100,000$ live births. The highest and lowest was recorded in the year 2014 and 2018 respectively.

As per Table 2, the highest number of maternal deaths $(130,42.62 \%)$ occurred in women of age group 21-25 years followed by 26-30 years age group (87, 28.52\%). Maternal deaths in the age group 18-20 years and 31-35 years were $33(10.82 \%)$ and $36(11.80 \%)$ respectively. Maternal deaths in the age group greater than or equal to 35 years were $19(6.23 \%)$. Maximum number of women came from urban area $(288,94.1 \%)$ than from rural areas $(18,5.9 \%)$. Majority of mothers were multipara (151, $49.51 \%)$ followed by primipara $(105,34.43 \%)$. Out of multiparous women, $28(9.18 \%)$ were grand multipara. Majority of maternal deaths were housewives (295, $96.72 \%)$ and illiterate $(54.75 \%)$ whereas $45.25 \%$ were literate.

Table 2: Maternal death and sociodemographic characteristics.

\begin{tabular}{|c|c|c|c|}
\hline Characteristics & Groups & $\begin{array}{l}\text { Maternal } \\
\text { deaths } \\
\text { (no.) }\end{array}$ & Percentage \\
\hline \multirow{5}{*}{ Age (years) } & $18-20$ & 33 & 10.82 \\
\hline & $21-25$ & 130 & 42.62 \\
\hline & $26-30$ & 87 & 28.52 \\
\hline & $31-35$ & 36 & 11.8 \\
\hline & $36-40$ & 19 & 6.23 \\
\hline \multirow{4}{*}{ Parity } & Nullipara & 49 & 16.07 \\
\hline & primipara & 105 & 34.43 \\
\hline & multipara & 151 & 49.51 \\
\hline & grand multipara & 28 & 9.18 \\
\hline \multirow{4}{*}{ Antenatal care } & Registered & 235 & 77 \\
\hline & $\geq 3$ & 166 & 54.43 \\
\hline & $<3$ & 69 & 22.62 \\
\hline & Unregistered & 70 & 23 \\
\hline \multirow{2}{*}{ Residence } & Urban & 288 & 94.1 \\
\hline & Rural & 18 & 5.9 \\
\hline \multirow{2}{*}{ Education } & Literate & 138 & 45.25 \\
\hline & Illiterate & 167 & 54.75 \\
\hline \multirow{2}{*}{ Occupation } & Housewife & 295 & 96.72 \\
\hline & Employed & 10 & 3.28 \\
\hline \multirow{2}{*}{ Referral status } & Referred & 238 & 78.03 \\
\hline & Direct & 67 & 21.97 \\
\hline \multirow{5}{*}{$\begin{array}{l}\text { Condition on } \\
\text { arrival }\end{array}$} & Conscious & 156 & 51.15 \\
\hline & Semiconscious & 88 & 28.85 \\
\hline & Gasping & 6 & 1.97 \\
\hline & Unconscious & 49 & 16.07 \\
\hline & Brought dead & 6 & 1.97 \\
\hline
\end{tabular}

The number of registered cases $(235,77.0 \%)$ were more than the unregistered $(70,23 \%)$. Out of the registered, $162(53.1 \%)$ had $\geq 3$ visits and $69(22.62 \%)$ had less than 3 antenatal visits.

Table 2 shows that majority were referred cases (238, $78.03 \%$ ). Out of the referrals, maximum cases (195, $81.93 \%$ ) were referred from within Mumbai and only 43 (18.07\%) were referred from outside Mumbai. As per Table 3, majority $(100,42.02 \%)$ were referred from private hospitals followed by peripheral Municipal hospitals (71, 29.83\%), outside Mumbai Municipal Corporation $(24,10.08 \%)$, maternity homes $(18,7.56 \%)$, 
district hospitals $(12,5.04 \%)$, urban health care centres $(6,2.52 \%)$, rural hospitals $(3,1.26 \%)$, government hospitals $(3,1.26 \%)$ and subdistrict hospitals $(1,0.42 \%)$.

Table 3: Type of referral facility.

\begin{tabular}{|c|c|c|c|}
\hline Place & $\begin{array}{l}\text { Type of referral } \\
\text { facility }\end{array}$ & No. & Percentage \\
\hline \multirow{4}{*}{$\begin{array}{l}\text { Mumbai } \\
(195, \\
\mathbf{8 1 . 9 3 \% )}\end{array}$} & Private hospitals & 100 & 42.02 \\
\hline & $\begin{array}{l}\text { Mumbai municipal } \\
\text { corporation }\end{array}$ & 71 & 29.83 \\
\hline & Maternity home & 18 & 7.56 \\
\hline & $\begin{array}{l}\text { Urban health care } \\
\text { centres }\end{array}$ & 6 & 2.52 \\
\hline \multirow{5}{*}{$\begin{array}{l}\text { Outside } \\
\text { mumbai } \\
(\mathbf{4 3}, \\
\mathbf{1 8 . 0 7 \% )}\end{array}$} & $\begin{array}{l}\text { Outside Mumbai } \\
\text { municipal } \\
\text { corporation }\end{array}$ & 24 & 10.08 \\
\hline & District hospitals & 12 & 5.04 \\
\hline & Sub district hospital & 1 & 0.42 \\
\hline & Rural hospitals & 3 & 1,26 \\
\hline & $\begin{array}{l}\text { Government } \\
\text { hospitals }\end{array}$ & 3 & 1.26 \\
\hline Total & & 238 & 100 \\
\hline
\end{tabular}

Table 4: Distribution of maternal deaths according to time of maternal death.

\begin{tabular}{|llll|}
\hline Time of maternal death & No. & Percentage \\
\hline Antepartum & 75 & 24.59 \\
\hline Intrapartum & & 1 & 0.33 \\
\hline \multirow{2}{*}{$\begin{array}{l}\text { Early } \\
\text { pregnancy } \\
\text { deaths }\end{array}$} & Post abortal & 22 & 7.21 \\
\cline { 2 - 4 } & Ruptured ectopic & 4 & 1.31 \\
\cline { 2 - 4 } & $\begin{array}{l}\text { Ruptured } \\
\text { rudimentary horn }\end{array}$ & 2 & 0.66 \\
\hline \multirow{2}{*}{ Postpartum } & Vaginal & 137 & 44.92 \\
\cline { 2 - 4 } & LSCS & 63 & 20.66 \\
\hline Total & Hysterotomy & 1 & 0.33 \\
\hline
\end{tabular}

Table 4 shows that the highest number of maternal deaths, $201(65.90 \%)$ occurred during postpartum period whereas $75(24.59 \%)$ were antepartum deaths. Early pregnancy deaths were $28(9.18 \%)$. There was one intrapartum death which was a case of primigravida with 33 weeks with RHD with MVR done with prosthetic valve dysfunction with LVF with PPROM. Out of the postnatal deaths there were $137(44.92 \%)$ vaginal deliveries and $63(20.66 \%)$ LSCS and 1 hysterotomy. Out of the 137 vaginal deliveries there were 4 outlet forceps, 1 vacuum delivery and 2 VBAC.

Table 5 shows that maximum cases of maternal deaths (222, 72.79\%) occurred within 7 days of admission amongst which 128 (41.67\%) occurred between 1-3 days of admission, $85(27.87 \%)$ deaths occurred within 24 hours and $3(0.98 \%)$ cases occurred between 3-7 days of admission. Eighty-three cases $(27.21 \%)$ occurred after 7 days of admission. Out of the total deaths, $6(1.97 \%)$ cases were brought dead to hospital.

Table 5: Distribution of maternal deaths and admission-death interval.

\begin{tabular}{|lll|}
\hline $\begin{array}{l}\text { Time interval between } \\
\text { admission and death }\end{array}$ & Number & Percentage \\
\hline 0 hours & 6 & 1.97 \\
\hline$<\mathbf{2 4}$ hours & 85 & 27.87 \\
\hline 1-3 days & 128 & 41.97 \\
\hline 3-7 days & 3 & 0.98 \\
\hline$>$ 7 days & 83 & 27.21 \\
\hline Total & 305 & 100.00 \\
\hline
\end{tabular}

Table 6 shows causes of maternal deaths which are categorized according to WHO application of ICD-10 to deaths during pregnancy, childbirth and puerperium: ICD-MM. ${ }^{4}$ Group 1, 2, 3, 4, 5 ,6, comprise of the direct causes whereas group 7 comprises of the indirect causes of maternal deaths. Group 8 comprises of deaths due to unknown or undetermined cause. Majority of maternal deaths $59.67 \%$ (182) were due to indirect causes, $40 \%$ (122) deaths occurred due to direct causes and $1(0.33 \%)$ death was due to unknown cause.

Table 6: Causes of maternal deaths as per WHO classification application of ICD-10.

\begin{tabular}{|llll|}
\hline Type & Group name/number & No. of deaths (n) N=305 & Percentage \\
\hline Maternal death: direct & Pregnancies with abortive outcome & 15 & 4.92 \\
\hline Maternal death: direct & $\begin{array}{l}\text { Hypertensive disorders in pregnancy, } \\
\text { childbirth, and the puerperium }\end{array}$ & 42 & 13.77 \\
\hline Maternal death: direct & Obstetric haemorrhage & 45 & 14.75 \\
\hline Maternal death: direct & Pregnancy-related infection & 11 & 3.61 \\
\hline Maternal death: direct & Other obstetric complications & 9 & 2.95 \\
\hline Maternal death: direct & Unanticipated complications of management & 0 & 0.00 \\
\hline Maternal death: indirect & Non-obstetric complications & 182 & 59.67 \\
\hline $\begin{array}{l}\text { Maternal death: } \\
\text { unspecified }\end{array}$ & Unknown/undetermined & 1 & 0.33 \\
\hline Total & & 305 & 100 \\
\hline
\end{tabular}


Table 7: Direct causes of maternal deaths $(n=122)$.

\begin{tabular}{|c|c|c|c|}
\hline \multicolumn{2}{|l|}{ Group name/number } & No. of deaths (n) $\mathrm{N}=122$ & Percentage \\
\hline \multirow{2}{*}{$\begin{array}{l}\text { Pregnancies with abortive } \\
\text { outcome }\end{array}$} & Abortions & 9 & 7.38 \\
\hline & Ectopic & 6 & 4.92 \\
\hline \multirow{4}{*}{$\begin{array}{l}\text { Hypertensive disorders } \\
\text { pregnancy, childbirth, and the } \\
\text { puerperium }\end{array}$} & Preeclampsia & 12 & 9.84 \\
\hline & Preeclampsia with HELLP & 12 & 9.84 \\
\hline & Eclampsia with HELLP & 17 & 13.93 \\
\hline & $\begin{array}{l}\text { Chronic hypertension with superimposed } \\
\text { preeclampsia with chronic kidney disease }\end{array}$ & 1 & 0.82 \\
\hline \multirow{6}{*}{ Obstetric haemorrhage } & APH & 10 & 8.2 \\
\hline & $\mathrm{PPH}$ & 18 & 14.75 \\
\hline & Placental & 3 & 2.46 \\
\hline & Broad ligament hematoma & 3 & 2.46 \\
\hline & $\mathrm{DIC}$ & 6 & 4.92 \\
\hline & Rupture uterus & 5 & 4.1 \\
\hline Pregnancy-related infection & Puerperal sepsis & 11 & 9.02 \\
\hline \multirow{4}{*}{ Other obstetric complications } & Peripartum cardiomyopathy & 3 & 2.46 \\
\hline & Amniotic fluid embolism & 2 & 1.64 \\
\hline & Pulmonary embolism & 2 & 1.64 \\
\hline & Acute fatty liver of pregnancy & 2 & 1.64 \\
\hline
\end{tabular}

Tables 6 and 7 shows that amongst the direct causes, haemorrhage $(14.75 \%)$ and hypertensive disorders $(13.77 \%)$ were maximum followed by abortive outcomes (4.92\%), sepsis (3.61\%), and other obstetric complications $(2.95 \%)$. There were no deaths related to complications due to anaesthesia.

Table 8: Indirect causes of maternal deaths $(n=182)$.

\begin{tabular}{|lll|}
\hline Causes & $\begin{array}{l}\text { No. of deaths } \\
\text { (n) N=182 }\end{array}$ & Percentage \\
\hline Anaemia & 5 & 2.75 \\
\hline Respiratory system & 25 & 13.74 \\
\hline CNS & 15 & 8.24 \\
\hline Cardiac & 15 & 8.24 \\
\hline Tuberculosis & 34 & 18.68 \\
\hline Hepatitis & 30 & 16.48 \\
\hline Dengue & 16 & 8.79 \\
\hline Leptospirosis & 7 & 3.85 \\
\hline H1N1 & 5 & 2.75 \\
\hline P. Vivax malaria & 3 & 1.65 \\
\hline Enteric fever & 1 & 0.55 \\
\hline Septicaemia & 12 & 6.59 \\
\hline Diabetic ketoacidosis & 4 & 2.20 \\
\hline Chronic hypertension & 1 & 0.55 \\
\hline Hemolytic uremic & 2 & 1.10 \\
\hline syndrome & 1 & 0.55 \\
\hline Portal hypertension & 2 & 1.10 \\
\hline Malignancy & 2 & 1.10 \\
\hline Autoimmune disorders & 2 & 1.10 \\
\hline Others & 2 & \\
\hline
\end{tabular}

Table 8 shows that tuberculosis $(34,18.68 \%)$ was the most common indirect cause of maternal mortality in our study followed by hepatitis $(30,16.48 \%)$ and respiratory infections $(25,13.74 \%)$. Also, infections like dengue (16, $8.79 \%)$, leptospirosis $(7,3.85 \%), \mathrm{H} 1 \mathrm{~N} 1(5,2.75 \%)$ and enteric fever $(1,0.55 \%)$ were few of the causes of maternal mortality. Septicaemia occurred due to 3 cases of perforative peritonitis, 1 of acalculous cholecystitis. 2 each of acute gastroenteritis, PUO and acute pyelonephritis and one case each of acute necrotising pancreatitis with ARDS and cellulitis. In CNS there were 7 cases of cerebral venous thrombosis, 3 cases of meningitis, 2 of sub arachnoid haemorrhage and 1 each of chronic brain abscess, operated case of posterior fossa grade 2 ependymoma and seizure disorder.

In respiratory disorders, there were 13 cases of ARDS, 6 of bronchopneumonia, 3 cases of bronchial asthma, one each of pneumonia, pleural effusion with consolidation and aspiration pneumonia. There were 8 cases of Rheumatic heart disease in cardiac maternal deaths. There was one case each of right renal angiomyolipoma and hepatocellular carcinoma. There were 2 cases of autoimmune disorders were one each of DIC in a case of Evans syndrome and SLE myositis. Other cases were one each of drug induced hypersensitivity, hypokalaemic periodic paralysis.

Table 9 shows that blood and blood products were transfused in 183 cases. Total obstetric hysterectomy was done in 22 cases, subtotal hysterectomy in 3, laparotomy in 5 cases and devascularisation procedure in 2 cases. One case each of bladder injury repair, broad ligament hematoma evacuation and B-lynch suture, ICD insertion for right sided pneumothorax, balloon mitral valvotomy and vaginal exploration with drainage of lateral wall hematoma was done. Relaparotomy was performed in 2 cases in which one was a case of post LSCS 
hemoperitoneum with oozing in the muscle with DIC and the second was a case of exploration twice for perforative peritonitis with sigmoid stoma creation an ileal perforation with resection of ileum with ileostomy following LSCS. Embolization of upper segmental branch of right renal artery was done in a case of MTP with exploratory lap with check curettage. Dialysis was done for 7 cases whereas craniotomy and tracheostomy were done in 5 cases. VP shunt was done in 4 cases.

Table 9: Associated surgeries/interventions performed.

\begin{tabular}{|l|l|}
\hline Interventions & Number \\
\hline $\begin{array}{l}\text { Multiple blood and blood products } \\
\text { transfusions }\end{array}$ & 183 \\
\hline Total hysterectomy & 22 \\
\hline Subtotal hysterectomy & 3 \\
\hline Dialysis & 7 \\
\hline Laparotomy & 5 \\
\hline Craniotomy & 5 \\
\hline Tracheostomy & 5 \\
\hline VP Shunt & 4 \\
\hline Devascularisation procedure & 2 \\
\hline Broad ligament hematoma evacuation & 2 \\
\hline Relaparotomy & 2 \\
\hline Manual removal of placenta (MROP) & 1 \\
\hline Bladder injury repair & 1 \\
\hline B-Lynch suture & 1 \\
\hline $\begin{array}{l}\text { ICD insertion done for right sided } \\
\text { pneumothorax }\end{array}$ & 1 \\
\hline Balloon mitral valvotomy & 1 \\
\hline $\begin{array}{l}\text { Vaginal exploration with drainage of } \\
\text { lateral wall hematoma }\end{array}$ & 1 \\
\hline Bakri balloon insertion & 1 \\
\hline $\begin{array}{l}\text { Embolization of upper segmental branch } \\
\text { of right renal artery by interventional } \\
\text { radiology }\end{array}$ & 1 \\
\hline
\end{tabular}

Exploration was done for ileal perforation following uterine and intestinal perforation in a case of attempted check curettage in known case of Koch's and a case of post LSCS sepsis. Out of the 22 obstetric hysterectomies, 13 were done in our institute and 9 in outside hospitals, indications of which were atonic PPH (7), bilateral broad ligament hematoma (2), bladder injury (1), DIC with hemoperitoneum (4), adherent placenta (1), placenta praevia with accrete (1) rupture uterus (2), scar rupture (1), abruption with atonic PPH (1), obstructed labour (1) and $\mathrm{PPH}$ following spontaneous abortion in a case of fibroid uterus (1). Subtotal hysterectomy was done in our institute for atonic PPH, puerperal sepsis and dengue haemorrhagic fever with atonic PPH following LSCS.

\section{DISCUSSION}

Maternal death is a tragic event which has a severe impact not only on the family but also on the community and the nation. Having a clear knowledge of the socioeconomic factors and the direct and indirect causes leading to maternal deaths can help to prevent maternal mortality.

\section{Maternal mortality ratio}

The hospital-based MMR in our present study (Table 10) was 666.75 per 100,000 live births. Other studies from tertiary care institutions reported mortality ratio of 234.6 to 940 per 100,000 live births. ${ }^{5-12}$

Low MMR was found in Shobha et al study (234.6), Patel et al (413.3), Boro RC et al (464) and Dayal et al (441) as compared to our study. ${ }^{5,9,11,12}$ Higher MMR was found in the study by Tadru et al (940) and Sundari et al (802). ${ }^{8,10}$

The maternal mortality ratio was quite high in our institution which was well above the national and state figures. As it is a tertiary hospital, it gets referrals from private nursing homes, municipality hospitals other level II hospitals, maternity homes, primary health care centres, district hospitals, and rural areas and its own booked cases. Also, it deals with high-risk patients. A total of 143 patients were in poor general condition on admission and needed ICU care with ventilator and ionotropic supports. Higher incidence of deaths was due to referral of complicated cases, late referrals from other centres and referral to two centres before reaching our institute leading to delayed treatment.

\section{Age distribution}

In our study, it was observed that maximum number of maternal deaths $(130,43 \%)$ were in age group of $21-25$ years and 87 (29\%) were in age group of 26-30 years. There were $36(12 \%)$ maternal deaths in age group 31-35 age and $33(11 \%)$ in 18-20 years. Maternal deaths seen in age group more than 35 years were 19 (6\%). A study by Tadru et al also showed that maximum number of maternal deaths $81(52.26 \%)$ were in age group of 21-25 years, followed by $40(25.81 \%)$ in age group of 26-30 years, $24(15.48 \%)$ maternal deaths in age less than or equal to 20 years, $7(4.51 \%)$ maternal deaths in age group $31-35$ years and $3(1.93 \%)$ maternal deaths were seen in age group more than 35 years. $^{8}$ A retrospective study by Sundari et al also showed that maximum number of deaths occurred between $21-25$ years $(64.2 \%) .{ }^{10}$

\section{Residence and occupation}

Maximum number of women came from urban area (288, $94.1 \%)$ than from rural areas $(18,5.9 \%)$. Majority of pregnant women were housewives $(295,96.72 \%)$ and illiterate $(54.75 \%)$ whereas $45.25 \%$ were literate. This is explained by the location of tertiary care institute in a metropolitan city. Also, our tertiary care centre caters to the largest slum area in Asia explained by the high rate of illiteracy and unemployed mothers. Other studies by Nair et al (52.9\%), Patel et al (67.3\%) and Khumanthem et al 
(77.5) showed maximum deaths in patients from rural areas. $^{7}$

\section{Parity}

In the present study, majority of mothers were multipara $(151,49.51 \%)$ followed by primipara $(105,34.43 \%)$. Out of multiparous women, $28(9.18 \%)$ were grand multipara. Maximum maternal deaths in multiparous women were also found in studies by Nair et al $(52.20 \%)$, Patel et al $(59.62 \%)$ and Sundari et al $(48.2 \%) .^{7,9,10}$ However in a study Shobha et al, primipara accounted for $73.77 \%$ of deaths. ${ }^{5}$ This shows that both multiparas and primiparas are at equal risk of having maternal mortality. Also, frequent pregnancies can affect the health of the pregnant women.

\section{Antenatal registration}

The number of registered cases $(235,77.0 \%)$ were more than the unregistered $(70,23 \%)$. Out of the registered, $162(53.1 \%)$ had $\geq 3$ visits and $69(22.62 \%)$ had less than 3 antenatal visits.

This was consistent with the studies by Boro et al and Sundari et al where the registered cases were $78.8 \%$ and $98.2 \%$ respectively. ${ }^{9,10}$ This shows that even though there were antenatal registrations, detection of high-risk factors, appropriate treatment and timely referral at each centre are very important to decrease maternal morbidity and mortality. In our study, only 42 cases were actually registered at our institute out of which 28 cases had more than 3 visits and 14 had less than 3 visits. Rest were registered in maternity homes, peripheral and private hospitals. The increased number of registered cases is explained by the urban location of our institute.

\section{Admission to death interval}

In our study, most cases i.e., $222(72.79 \%)$ died within 7 days of admission among which 128 (41.67\%) of maternal deaths occurred between 24-72 hours of admission and $85(27.87 \%)$ deaths occurred within 24 hrs. Eighty-three cases $(27.21 \%)$ occurred after 7 days of admission. This was similar to a study by Shobha et al where maximum deaths $(36,59.01 \%)$ occurred within a week of admission), among these 13 (21.31\%) women died within twenty-four hours of admission to hospital. ${ }^{5}$ In contrast, other studies showed early deaths of $48.2 \%$, $44.90 \%$ and $96.1 \%$, within 24 hours of admission. ${ }^{6,7,9}$ Availability of intensive care unit, blood bank and multidisciplinary team with interventional procedures delayed the admission death interval in our study.

\section{Mode of delivery}

In our study, highest number of maternal deaths, 201 (65.90\%) occurred during postpartum period whereas 75 $(24.59 \%)$ were antepartum deaths. There were 22 (7.21\%) cases due to abortion. This was comparable to other studies by Shobha et al $(88.52 \%)$ Rajeshwari et al (5) $(69.2 \%)$ and Patel et al 69.23\%.4,5,10

Table 10: MMR and percentage causes of deaths in different areas in India.

\begin{tabular}{|c|c|c|c|c|c|}
\hline Study & Year & MMR & $\begin{array}{l}\text { Haemorrhage } \\
(\%)\end{array}$ & $\begin{array}{l}\text { Sepsis } \\
(\%)\end{array}$ & $\begin{array}{l}\text { Hypertensive disorders in pregnancy } \\
(\%)\end{array}$ \\
\hline Shobha et $\mathbf{a l}^{5}$ & Jan 07-Dec 16 & 234.6 & 13.11 & 9.83 & 21.31 \\
\hline Rajeshwari et al ${ }^{6}$ & June 09-May14 & 544 & 35 & 6 & 39.4 \\
\hline Nair et al $^{7}$ & Jan 12-Dec14 & 410 & 33.80 & 8.20 & 10.30 \\
\hline Tadru et al $^{8}$ & July 13-June18 & 940 & 18.70 & 3.87 & 22.56 \\
\hline Boro et al $^{9}$ & March 14-Feb 16 & 464 & 25 & 9.61 & 19.3 \\
\hline Sundari etal ${ }^{10}$ & Jan 15-Dec 15 & 802 & 17.8 & 12.5 & 26.78 \\
\hline Patel et al $^{11}$ & Jan 16-Dec 17 & 413.3 & 28.8 & 13.46 & 17.3 \\
\hline Dayal et al $^{12}$ & Jan 17-Dec 18 & 441 & 36.66 & 12.5 & 23.33 \\
\hline Our study & Jan 14-Dec 18 & 666.75 & 14.75 & 3.61 & 13.77 \\
\hline
\end{tabular}

\section{Analysis of causes of death}

The present study shows reduction in proportion of deaths due to direct causes. Deaths due to indirect and direct causes were $59.67 \%$ and $40 \%$ respectively, which was similar to the study done by Parmar et al. ${ }^{13}$ In the study by Parmar et al, $40 \%$ of maternal deaths were due to direct causes which were less than the indirect causes. In the studies by Shobha et al Rajeshwari et al, Nair et al,
Tadru et al and Patel et al the direct causes were more as compared to indirect causes. ${ }^{5-8,11}$

Table 10 depicts that in our study among the direct causes of maternal deaths, majority $(42,16.72 \%)$ were from haemorrhage which was similar to the studies by Nair et al, Boro et al, Patel et al, Dayal et al, Parmar et al and Sethi et al where the maternal deaths due to haemorrhage have been reported to vary between $9.72 \%$ to $55.7 \%$. $^{7,9,11-}$ 14 Hypertensive disorders were highest in studies by 
Shobha et al, Rajeshwari et al, Tadru et al and Sundari KPM et al. ${ }^{5,6,8,10}$ In the study by Shobha et al preeclampsia and eclampsia, acute fatty liver of pregnancy, haemorrhage, sepsis and anaemia were the common causes of maternal deaths. ${ }^{5}$

Tuberculosis $(34,18.6 \%)$ was the most common indirect cause of maternal mortality in our study followed by hepatitis $(30,16.48 \%)$ and respiratory infections $(25$, $13.74 \%$ ). Anaemia was the commonest cause of maternal death in studies by Shobha et al, Rajeshwari et al, Nair et al, Dayal et al and Khumanthem et al. ${ }^{5-7,12,15}$ In our study there were varied presentations of tuberculosis with a predominance of secondary tuberculosis. There were 11 cases of disseminated tuberculosis, 8 of tuberculous meningitis, 3 each of miliary $\mathrm{TB}$ and pulmonary tuberculosis, 2 each of MDR TB, Post TB sequelae with left sided bullous lung disease. There was one case each of hilar lymph node tuberculosis, progressive secondary tuberculosis with dilated cardiomyopathy, tuberculous bronchopneumonia and pulmonary Koch's obstructive airway.

In the study by Tadru et al, majority of the deaths 12 $(7.74 \%)$ were due to respiratory conditions (except TB and $\mathrm{H} 1 \mathrm{~N} 1)$ and due to hepatitis $12(7.74 \%) .{ }^{8}$ Other causes of deaths were central nervous system disorders (8, $5.16 \%)$, cardiac diseases $(7,4.51 \%)$, septicaemia and septic shock $(6,3.87 \%)$, H1N1 $(3,1.93 \%)$, anaemia $(2$, $1.29 \%)$, TB $(2,1.29 \%)$, dengue $(1,0.65 \%)$ and deaths due to other causes $(4,2.58 \%)$. These findings were consistent with our study.

In 2013, 3.3 million tuberculosis cases and 5,10,000 tuberculosis deaths were estimated to occur in women globally. ${ }^{16}$

According to a study by Sugarman et al, it was estimated that there were 2,16,500 pregnant women with tuberculosis globally in 2011. ${ }^{17}$ The Africa WHO region and South East Asia WHO region carry the greatest burden of tuberculosis cases among pregnant women, with 89,400 (41\% of global burden) and 67,500 (31\% of global burden) cases, respectively. The country with the highest number of cases in pregnant women was India (44,500 or $21 \%$ of the global tuberculosis burden), which reflects the high tuberculosis burden in the general population, the country's large population, and its high birth rate.

Worldwide, an estimated 900 million women have a latent Mycobacterium tuberculosis infection (LTBI), and pregnant women with LTBI are more likely to progress to developing active tuberculous disease than men. It has long been observed by obstetricians that pregnancy is associated with a more prevalent onset of active tuberculosis (TB) and also more rapid progression of TB disease compared with the non-pregnant state. ${ }^{18}$
According to a review of literature done by Nguyen et al the major problem concerning TB diagnosis for pregnant women is the delay in diagnosis, ranging from 7 days to 6 months due to women seeking health services and prenatal care at a late stage of their pregnancy and that TB during pregnancy is asymptomatic or has nonspecific symptoms, especially in cases of extra pulmonary TB. The results also showed that a delay in, or default of MDR treatment were the main causes of mortality and morbidity for mothers and babies. ${ }^{19}$

Therefore, there is a need for antenatal surveillance for Tuberculosis in pregnant women. This can be achieved by active screening of antenatal pregnant women at the time of first registration by looking for presumptive symptoms of tuberculosis such as low-grade fever associated with cough for a duration of 14 days, weight loss associated with loss of appetite. Special attention to be given to pregnant women with a past history of Tuberculosis. Such patients to be screened at regular visits and followed up till term and postpartum for any signs of reactivation of tuberculosis.

As observed in the present study, 211 pregnant women failed to seek treatment and were noncompliant. This was due to unregistered cases and delay in seeking care. The reasons for this were female illiteracy, employment status and poor family support because of which these women received poor antenatal care. Most of the cases (53) were referred due to lack of blood and blood products, a need of ICU care, lack of operative facilities and also due to non-affordability of treatment. It was also found that these women had to seek treatment from one or two referral centres before they reached our institution. Therefore, they reached the hospital in a moribund condition. Despite facilities at our tertiary centre, we could not save the lives of these women. Therefore, it is highly recommended to provide essential obstetric care to all antenatal patients at the first and second referral centres. Doctors and staff should be trained in performing surgical procedures like caesarean sections and safe abortions in the first and second referral centres. Also, mass education in the community regarding importance of antenatal visits and tuberculosis awareness need to be carried out along with the help of the national programmes.

There are some limitations of the study. The retrospective nature of the study based only on hospital-based records of death summaries and the absence of any control study group were the limitations of the study. As only maternal deaths occurring in our hospital were studied, the findings could not be generalized to the entire population. Therefore, the ratio of maternal mortality of our hospital was found to be larger than that of nation.

\section{CONCLUSION}

In the present study many of the causes of maternal mortality could have been prevented by adequate 
surveillance of tuberculosis in the antenatal period, health education of pregnant women, proper antenatal, intranatal and emergency obstetric care in the first referral unit with proper blood banking facilities and timely referral to the tertiary care institute. Also early antenatal registrations of high risk pregnancies to be encouraged in the tertiary care institute so that they can be managed with a multidisciplinary team.

Funding: No funding sources

Conflict of interest: None declared

Ethical approval: The study was approved by the Institutional Ethics Committee

\section{REFERENCES}

1. World Health Organization. (2019). Trends in maternal mortality 2000 to 2017: estimates by WHO, UNICEF, UNFPA, World Bank Group and the United Nations Population Division: executive summary. World Health Organization. Available from: https://apps.who.int/iris/handle/10665/327596. Accessed on 4 January 2021.

2. MMR bulletin- 2014-2016 Special Bulletin on Maternal Mortality in India 2014-16 Sample Registration System, Office of Registrar General, India. Available from: https://censusindia.gov.in/vital_statistics/SRS_Bullet ins/MMR\%20Bulletin-2014-16.pdf. Accessed on 4 January 2021.

3. MMR bulletin- 2016-2018. Special Bulletin on Maternal Mortality in India 2016-18 Sample Registration System, Office of Registrar General, India. Available from: https://censusindia.gov.in/vital_statistics/SRS_Bullet ins/MMR\%20Bulletin\%202016-18.pdf. Accessed on 4 January 2021.

4. World Health Organization. The WHO Application of ICD-10 to Deaths During Pregnancy, Childbirth and the Puerperium: ICD-MM. Geneva, Switzerland: World Health Organization, 2012. Available from: www.who.int/reproductivehealth/publications/monit oring/9789241548458/en/. Accessed on 1 January 2021.

5. Shobha G, Jayashree VK, Veena BD, Thomas A. Review of maternal mortality in a tertiary care urban teaching hospital: 10 year retrospective study. Int J Reprod Contracept Obstet Gynecol. 2019;8:2050-3.

6. Rajeshwari S. Maternal mortality in an urban tertiary care hospital of south India. Indian J Obstet Gynaecol Res. 2016;3(1):32-7.
7. Nair A, Doibale MK, Gujrathi VV, Inamdar IF, Shingare AD, Rajput PS. Study of maternal mortality in a tertiary care hospital in a district of Maharashtra. Int J Med Sci Public Health. 2016;5:1851-4.

8. Tadru DS, Sirsam DS, Purohit DN. Review of maternal mortality at tertiary care hospital in Vidarba region of Maharashtra. Int $\mathbf{J}$ Contracept Gynaecol Obstet. 2019;1(1):07-13.

9. Boro RC, Sarma P, Acharjee PS. Causes of maternal deaths at Tezpur medical college and hospital $(\mathrm{TMCH})$, Tezpur, Assam, India: a retrospective study. Int J Reprod Contracept Obstet Gynecol. 2016;5:1006-9.

10. Sundari KPM, Jayanti RD, Ramaswamy B. Trends in a tertiary care hospital. Int $\mathrm{J}$ of Reprod Contracept Obstet Gynecol. 2016;5(11):3659-62.

11. Patel DM, Patel MM, Salat VK. Two year review of maternal mortality at a tertiary care hospital of GMERS, Valsad, Gujarat, India. Int J Reprod Contracept Obstet Gynecol. 2018;7:2283-6.

12. Dayal DN, Srivastava, DA. A retrospective study of maternal mortality in a tertiary care hospital. IOSR J Dent Med Sci. 2019;18(4.12):15-8.

13. Parmar M, Shrivastava S, Kanhere A, Patel S. Maternal mortality: a retrospective analysis of 6 years in a tertiary care centre. Int $\mathbf{J}$ Reprod Contracept Obstet Gynecol. 2018;7:224-8.

14. Sethi PS, Sharma S, Chawla I. Maternal mortality in a tertiary care centre in North India: a retrospective study. Int J Reprod Contracept Obstet Gynecol. 2017;6:5559-62.

15. Khumanthem PD, Chanam MS, Samjetshabam RD. Maternal mortality and its causes in a tertiary center. J Obstet Gynaecol India. 2012;62:168-71.

16. World Health Organization. Global tuberculosis report 2014.Geneva, 2014. Available from: https://www.who.int/tb/publications/global_report/gt br14_main_text.pdf. Accessed on 1 January 2021.

17. Sugarman J, Colvin C, Moran AC, Oxlade O. Tuberculosis in pregnancy: an estimate of the global burden of disease. Lancet Glob Health. 2014;2(12):e710-6.

18. Bates M, Ahmed Y, Kapata N, Maeurer M, Mwaba $\mathrm{P}$, Zumla A. Perspectives on tuberculosis in pregnancy. Int J Infect Dis. 2015;32:124-7.

19. Nguyen HT, Pandolfini C, Chiodini P, Bonati M. Tuberculosis care for pregnant women: a systematic review. BMC Infect Dis. 2014;14:617.

Cite this article as: Sarmalkar MS, Nayak AH, Faisal $\mathrm{S}$, Abhakumari. A five-year retrospective study of maternal mortality in a tertiary referral centre. Int $\mathrm{J}$ Reprod Contracept Obstet Gynecol 2021;10:1935-42. 